\title{
Frequent Crisis and Modern Trends Associated with HAZOP Study in Plants and Industrial Units
}

\section{Kunal Sharma ${ }^{1}$, Dr Rahul Lodha ${ }^{2}$}

${ }^{1}$ Research Scholar, Department of Chemical Engineering, Mewar University, Gangrar, Chittorgarh, Rajasthan, India

${ }^{2}$ Associate Professor, Department of Chemical Engineering, Mewar University, Gangrar, Chittorgarh, Rajasthan, India

\begin{abstract}
Article Info

Volume 7, Issue 6

Page Number: 43-50

Publication Issue :

November-December-2020

\section{Article History}

Accepted : 01 Nov 2020

Published : 06 Nov 2020

Hazard and operability (HAZOP) analysis has a well-deserved reputation for systematic and thorough evaluation of process hazards in industrial units. The method is now widely known and is in prevalent use in the chemical processing industries; so much so that in many industries performing a HAZOP has become a legal requirement for new or modified industrial units. A number of guides exist for conducting HAZOPs, the most recent being the IChemE guidelines on finest practice - second edition, published in the year 2008. In exercise however, following best practice is not that easy and many compromises have to be made in order to finish the task an added hurdle occurs when the HAZOP is led by a self-governing leader from an external company or third party as is increasingly the case. In this circumstance the person in charge also has to satisfy the customer or customer's requirements which do not always match to the best custom.

In addition there is a drift to lessen HAZOP study scope to safety health and environmental concerns only and to exclude operability and consistency issues. This has resulted from a observance mindset, possibly in an attempt to lessen liabilities. HAZOP is increasingly being seen as a conformity tool rather than as a tactic to ensure a secure, trustworthy and well designed plant. With the current financial environment we can expect these hitches to increase as project costs come under enhanced pressure and the extent of many projects is reduced. This paper discusses some of the more frequent crisis that occur during HAZOPs and some of the possible solutions in industrial units.

Keywords : HAZOP, Industrial Process Safety
\end{abstract}

\section{INTRODUCTION}

HAZOPs are used to identifying both hazards and operability problems. Although hazard identification is the main focus, operability problems are also identified to the extent that they have the potential to lead to safety or environmental hazards, or have a negative impact on plant profitability. Hazard and operability studies (HAZOP) were build up in late 1960s by ICI following some major crisis with newly

Copyright: (C) the author(s), publisher and licensee Technoscience Academy. This is an open-access article distributed under the terms of the Creative Commons Attribution Non-Commercial License, which permits unrestricted noncommercial use, distribution, and reproduction in any medium, provided the original work is properly cited 
built process plants. The methodology is now widely known and is in prevalent use in the chemical industrial processing industries worldwide and has a well-deserved status for systematic and thorough evaluation and findings of process hazards and operability issues. A number of guides exist for performing HAZOPs, the most recent being guidelines on best practice - second edition, published in 2008 by IChemE.

\section{THE HAZOP PROCESS}

The HAZOP team focuses on specific portions of the process called "nodes". Generally these are identified from the P\&ID prior to the study by the Hazop chairman. A process parameter is identified, e.g. flow. Then a series of guidewords is combined with the parameter "flow" to create a deviation. For example, the guideword "no" is combined with the parameter flow to give the deviation "no flow". The team then focuses on listing all the credible causes of a "no flow" deviation beginning with the cause that can result in the worst possible consequence the team can think of at the time. Once the causes are recorded the team lists the consequences, safeguards and any recommendations deemed appropriate. The process is repeated for the next deviation and so on until completion of the node. The process is repeated for all other nodes.

In exercise however, following paramount practices is not always simple and many conciliations have to be made in order to finish the job. Sometimes HAZOP is not the finest tool to use at the inception design time review and certain other techniques are more appropriate. The term HAZOP has become everpresent with process hazard study in chemical industrial units and many industries refer to HAZOPs when they actually mean different types of hazard studies. In some cases this may lead to HAZOPs being exercised at the erroneous stage of a project leading to them having to be repeated later.

There are a number of frequent crisis that happen during HAZOPs that are not discussed in specified guidelines but are discussed below along with some probable elucidations. In addition there is a inclination to reduce HAZOP study scope to safety and environmental concerns only and to prohibit operability and reliability issues. With the recent fiscal climate we can expect this drift to increase as project costs come under increased pressure and project administrators attempt to reduce costs.

A number of industries are now focusing on an independent facilitator from an external ageny or third party to organize the HAZOP study. This requirement for self governance and positive objectivity is clearly beneficial although it does append some crisis to the HAZOP task that requires robust management.

\section{THE SAFETY STUDY COURSE OF ACTION}

In a typical industrial unit, projects typically undergo numerous process hazard study assessments. These occur at different stages in the development of the industrial unit projects. According to some best practice quotations the process usually comprises of eight major stages; the typical six stages which are often called process hazard studies 1 to $6 \&$ two additional stages $(0 \& 7)$. These are shown in below table. Preferably all eight reviews will be exercised during length of a project along with supplementary HAZOP reviews every few months during the operating phase. Traditionally various organisations fail to perform all these reviews. The typical HAZOP study is the stage 3 process hazard study applied to a design during the detailed engineering phase with firm P\&IDs and other engineering support documentation. 


\begin{tabular}{|l|l|}
\hline \multicolumn{3}{|c|}{ Table 1 Process Hazard Studies } \\
\hline $\mathbf{2}$ & \multicolumn{1}{|c|}{ Process Hazard Study } \\
\hline & $\begin{array}{l}\text { Consideration of inherent safety or less } \\
\text { polluting } \\
\text { systems (research or inception stage) }\end{array}$ \\
\hline $\mathbf{1}$ & Concept stage hazard evaluation \\
\hline $\mathbf{2}$ & $\begin{array}{l}\text { FEED or project characterization hazard } \\
\text { evaluation }\end{array}$ \\
\hline $\mathbf{3}$ & $\begin{array}{l}\text { Comprehensive design HAZOP } \\
\text { performed during the operating phase) }\end{array}$ \\
\hline $\mathbf{4}$ & Construction/design verification \\
\hline $\mathbf{5}$ & Pre-commissioning \\
\hline $\mathbf{6}$ & Project close out/process start-up \\
\hline $\mathbf{7}$ & Abandonment \\
\hline
\end{tabular}

\section{HAZOP METHODOLOGY}

The HAZOP methodology has been described in detail in diverse guides. It is not our point here to discuss this in detail. For a typical evaluation it consists of the following stages:

\section{Table 2 Stages of HAZOP}

\begin{tabular}{|ll|}
\hline Stage & \multicolumn{1}{c|}{ Job } \\
\hline First & $\begin{array}{l}\text { Concurrence of terms of reference and } \\
\text { limitations of the study }\end{array}$ \\
\hline Second & \begin{tabular}{l} 
Detailing the sections/nodes for the study \\
\hline Third
\end{tabular} \\
& $\begin{array}{l}\text { Nodes description and design intent of the } \\
\text { node concurrence }\end{array}$ \\
\hline
\end{tabular}

Fourth Deviation generation by systematically applying com-binations of all important parameters and guidewords

Fifth Practical cause identification of deviations and probable consequences

Sixth Uphold evaluation and passable decision \& understand requirement of changes

Seventh Methodically document the key findings and any recommendations

Eighth Follow up and close out

\section{MODERN DRIFT}

In last decade there is a drift to reduce the HAZOP study scope to identify safety and environmental concerns only and to exclude operability and reliability issues. Although rate control by project management has played a task in this, the major reason for this drift appears to have resulted from an observance approach. HAZOPs are considered a safety need and any findings become legal requirements in various industries with costly implications and on-going controls.

As a consequence, clients and especially their safety advisors want to mitigate findings \& action items. Eliminating findings relating to operability and reliability is one way of achieving this, although a simpler approach of categorising findings into industrial safety, environmental and other would probably be wiser and at least one unit has developed a procedure to screen out these issues prior to HAZOP based on the observation that most (something like 90\%) of items have been identified before in earlier HAZOPs and an extra re-evaluate has been added into the project development process to identify these items and resolve them.

Another continuing drift is the use of the word HAZOP to consign all safety related studies rather than using it for its true meaning. For some industries this has created real problems and unnecessary costs as their formal procedures require them to perform a HAZOP even when a different type of review such as a process hazard study 2 or HAZID would be more appropriate.

\section{FREQUENT ISSUES}

The following are some of the more frequent issues that occur during HAZOPs and some of the probable solutions. Very slight guidance is given on these in the guidelines: 


\section{HAZOP BY DISPARITY}

HAZOP by disparity is a applicable technique for dealing with recurring designs. It is commonly used on a minute scale in many HAZOPs where there are similar pieces of apparatus. One piece is reviewed and the findings then applied to the others. Some dialogue should also take place on any probable interactions between the parallel streams with all or only some of the units on line and how the flow distribution will be controlled.

Where HAZOP by disparity can easily become a difficulty is where similar equipment such as Merchant packages are installed in different units. The preliminary issue that needs resolving is determining what is different from the previously HAZOP studied case. It is easy to fall into the catch of only focussing on the hardware changes such as construction materials or design pressures etc. And not to deem all the process conditions of the plant that the equipment is connected too. Any changes in these conditions required identification as these can impact on the package operation. It is rare for there not to be any important changes. The methodology we have found most triumphant is to consider the interfaces in turn and where differences are identified be relevant the appropriate parameter/guideword combinations. Important care must be taken as if there are numerous already existing unidentified changes, sometimes this can take longer than doing a predictable HAZOP anyway.

The other important topic with HAZOP by difference is determining an adequate number of repeats before a totally new HAZOP should be done. In the same way as operating industrial units should endure a HAZOP study every few years, repetitive designs should be revisited. A variety of options are possible, for example, every three years or after every two HAZOP by differences. Ideally the team head should reassess the previous HAZOP by difference and use his moderation to determine if it would be better to execute a new HAZOP.

\section{MERCHANT AND LICENSOR PACKAGES}

Merchant and Licensor packages present particular challenges. They are usually processed by using HAZOP by difference and the previously mentioned crisis. In addition there is often unwillingness by a Merchant or licensor to recognize that there may be other problems with their design that should be resolved. The typical squabble is that the package/design has already been through a HAZOP and there have not been any failure incidents on their units so it is safe. As it is impracticable to do a proper HAZOP without considering all the peripheral connections and interfaces which are different in each case, this dispute is wrong. One of the major challenges the HAZOP facilitator will face is getting positive involvement from the Merchant who may only be attending the HAZOP because of a contractual obligation.

Even if changes are acceptable to the Merchant then it can add extremely to the budget. Re-engineering a design is generally not recommended and although the re-engineering should not take place in the HAZOP, the wording of any recommendations can easily lead to re-engineering later even if other options to resolve the issues are available. Another frequent problem is the Merchant's reluctance to share important information about their design for competitive causes. This is typically resolved by having numerous confirmations of detail type action items; although the HAZOP facilitator needs to ensure that in situations with a particularly high risk, the action is followed through more than just by receiving a confirmation type response from the Merchant. 
Sometimes a HAZOP of entire unit is called for but the Merchants demand are not as well mentioned in documents as the rest of the unit and are therefore not practically suitable for HAZOP. In this case the safest and clear move is often to execute a process hazard study or HAZID on the demands or a What-if type of study. This can provide precious feedback into preliminary stage i.e, the design allowing changes to be made relatively easier than would be the case if the demand is ignored until a HAZOP is practically feasible. It is important that the minutes show this evidently and that an action to do a HAZOP on the demand when possible is included.

\section{INSUFFICIENT INFORMATION OR ACCESSIBLE DETAILS}

Persistence of such situation is usually seen during HAZOP studies and it always create problem. Ideally, the HAZOP should be exercised on stable P\&IDs, frozen for the HAZOP and all required documentation should be available. In practice it is exceptional that this happens, the HAZOP dates are set deadlines, often locked months in advance; and the engineering often administers such problems causing delays. So the only suppleness available is the quality of the information provided. The other common reason for this problem is the effort to exercise a HAZOP too early in the project development when a different study such as a process hazard study or HAZID would be more appropriate. The reasons for this were discussed earlier.

When this type of problem comes into picture, it is up to the HAZOP facilitator on how to handle the crisis. In some cases, if the requisite information can be made available within few hours or days it is preeminent to move on to another parameter or node and then come back later. Sometimes it is superlative to proceed based on an assumption which can be confirmed later or added as an action item. If a particular section of the unit is completely lacking in details or the team knows that it has recently undergone major changes which are not yet shown on the drawings, it is often best to leave it out and move on with an action to ensure it is HAZOPd later. Often the choice of the finest approach is determined by the logistics and the availability of the contributors. If persons have travelled to the HAZOP from different places as is often the case, then it is significant that they are utilised as superlative as possible. Organising a second HAZOP will probably be out of the question.

\section{INTEGRATING DIFFERENT STUDIES ALONG WITH THE HAZOP}

This is a fresh development and is typically an effort to reduce schedule and industries costs. When a request to do this occurs, it shows a lack of understanding of the process safety review process that is being exercised. Ideally the SIL assessment follows the process hazard study or HAZID with a gap of at least several weeks so that changes resulting from the HAZID can be followed up prior to HAZOP. The HAZOP should be performed on the design once the observations and recommendations of the SIL assessment, especially equipment details, have been included in the design.

It is likely to do a SIL assessment following a HAZOP, but any resulting significant changes identified in the SIL evaluation will have to be reviewed in a later stage of HAZOP process. If the choice is made to do a SIL evaluation immediately after a HAZOP, make sure that sufficient time is budgeted to do both, trying to constrict a SIL assessment into the time originally allocated for a HAZOP will simply not work.

\section{USE OF HAZOP AS AN EDUCATION TOOL}

The HAZOP process provides an ideal opportunity for participants to learn about the process from the past era. The HAZOP typically occurs at a stage when operating employees are allocated to the venture and 
it is common for different contributors to have no experience of the particular process apart from two or three weeks of preparation. Sometimes two or three such members are on the team. As per my outlook this should be encouraged as the more the people running the plant understand about the process, the better input they will have into the design and the safer the plant will be. However it is important that too much time is not taken up in explaining the details of the process rather than doing the HAZOP. Someone who has actually operated a similar unit for long should always be on the HAZOP team. In various cases this turns out to be the licensor or a third party evaluator as the operating unit may not have any such individuals available.

\section{INADEQUATE TIME}

There is always load on a team head to lessen the time taken to do the HAZOP for schedule and cost reasons. A thorough HAZOP takes time to be performed properly and short cuts should not be taken.Based on prior knowledge \& expertise, the HAZOP team leader will be able to approximate the time requirements by reviewing the unit drawings. The approximation is likely to be different to that in the assignment and the head must agree the time requirements with the project manager whilst finalising the terms of reference.

If deficient time is allocated, then it is better to leave areas out of the review rather than conciliate on the quality. If quality is compromised there are numerous implications and this could result in the whole HAZOP having to be redone. It is possible to speed things up a little through selecting larger nodes and working extra hours but there are limits to this.Ideally an extra day will be built into the schedule to allow for contingencies, this is especially important when people have to travel to the HAZOP from around the world as is often the case. Letting them leave early is always easier than extending their stay.

As the HAZOP advances, it will become lucid if there is going to be an overrun. It is imperative for the head to discuss this with the project lead as soon as possible and agree on how it will be handled.

\section{COMMUNICATION ISSUES}

In big or giant units, it is not uncommon for HAZOPs to be conducted in a language that is not the common language of some of the stakeholders. This can be a complicated situation to handle and the head needs to be tactful to confirm that all members of the HAZOP team can participate equally and contribute to the session.

Sometimes it is necessary to use a local interpreter for conducting the exercise. The head and interpreter must develop a good working association for it to be successful. The interpreter must also have a good understanding of the technical details of the procedure and have participated in HAZOPs before. The use of a local interpreter often results in multiple discussions taking place at the same time, something that is considered contrary to good practice. Usually it is better to allow the conversations to take place independently and then feedback the results to the leader. Trying to have one to one discussions via an interpreter doesn't work. Allow important extra time if an interpreter is required.

\section{CULTURAL ATTITUDE TOWARDS SAFETY}

In many parts of the countries a hazard based approach to safety is not used or understood and either a fulfilment mindset is present or in some cases a more informal attitude to safety is present. In severe cases the two approaches result in either minimal actions, only those absolutely necessary by local governing law; or alternatively a denial to believe that operators will make mistakes and will always 
successfully follow detailed procedures so that no other safeguards are necessary.

Dissimilar people in the same HAZOP team are likely to have these unlike attitudes and part of the leader's job is to overcome these differences and get the team to work together. These differences should not affect the findings of the HAZOP in terms of concerns or hazards identified, but are likely to influence the recommended actions. The head should never negotiate his integrity and accept lower standards. The Institution of Chemical Engineer's Rules of Professional Conduct and Disciplinary Regulations, Issue 3, 7 December 2001, state:

It is very evident that local ways of doing things should be acceptable to the team composition, but this may not always be the case. At the end of the day the head's role is to run the HAZOP and identify potential safety and other problems for the client to take action on. The operating company is responsible for operating the plant safely and responding to the actions. Phrasing the actions in such a way as to enable flexibility in the response is one way of handling this situation, but care must be taken not to dilute the importance of the situation.

\section{PURSUING HAZOP ACTIONS}

This is a very frequent hitch. Often the recommendations are not dealt with or not dealt with proper appropriation or seriousness. It is significant that there is a single point of responsibility for this and an auditing activity takes place to make sure follow up. Approval or rejection of the actions also requires an experienced engineer at a senior level in the organisation who has the authority to make decisions. Some units follow the practise to make the HAZOP head responsible for the close out of the actions, although with the use of independent or external HAZOP exerciser this is not usually feasible.

\section{CONCLUSION}

HAZOP is the preferable method for risk management in the pharmaceutical industry as HAZOP analysis include higher consistency, better quality, increased safety and its contribution towards cost saving includes decreased expansion time and reduced waste and non-value added procedures. The HAZOP process is based on the principle that a team approach to hazard analysis will identify more problems than when individuals working separately combine results.

The HAZOP team is made up of individuals with varying backgrounds and expertise. Hazard and operability studies (HAZOP) have a well deserved status for systematic and thorough evaluation, assessment and identification of process hazards. A number of guides for performing HAZOPs exist but these do not cover all of the problems involved in performing the HAZOPs. This paper has discussed some of the basic problems that comes into picture during HAZOPs along with some possible solutions to that in the hope that such points may lead to improved quality of HAZOP studies and resultant improved plant safety and performance.

\section{REFERENCES}

[1]. ASME. ASME BPVC-VIII-1: ASME Boiler and Pressure Vessel Code, Section VIII, Division 1: Rules for Construction of Pressure Vessels; ASME International: New York, NY, USA, 2015.

[2]. Baron, H. The Oil \& Gas Engineering Guide, 3rd ed.; Editions TECHNIP: Paris, France, 2010.

[3]. Crowl, D.A.; Louvar, J.F. Chemical Process Safety: Fundamentals with Applications, 2nd ed.; Pearson Education:London, UK, 2001.

[4]. EPSC, 2008. Hazop guide to best practice, 2nd edition, IChemE. 
[5]. Fabiano, B.; Vianello, C.; Reverberi, A.P.; Lunghi, E.; Maschio, G. A perspective on Seveso accident based on cause-consequences analysis by three different methods. J. Loss Prev. Process Ind. 2017, 49, 18-35. [CrossRef]

[6]. Kletz, T., 2006, HAZOP and HAZAN, 4th edition, IChemE. AIChE, 1992, Guidelines for hazard evaluation procedures, AIChE.

[7]. Nolan, D.P., 1994, Application of hazop and what-if safety review to the petroleum, petrochemical and chemical industries, Noyes publications.

[8]. OECD. OECD Guidelines for the Testing of Chemicals/OECD Series on Testing and Assessment Harmonised Integrated Classification System for Human Health and Environmental Hazards of Chemical Substances and Mixtures; OECD: Paris, France, 2001.

[9]. Pasman, H.J.; Rogers, W.J.; Mannan, M.S. How can we improve process hazard identification? What can accident investigation methods contribute and what other recent developments? A brief historical survey and a sketch of how to advance. J. Loss Prev. Process Ind. 2018, 55, 80-106. [CrossRef].

[10]. UN. Globally Harmonized System of Classification and Labelling of Chemicals (GHS), 4th ed.; UN: Geneva, Switzerland, 2011.

\section{Cite this article as :}

Kunal Sharma, Dr Rahul Lodha, "Frequent Crisis and Modern Trends Associated with HAZOP Study in Plants and Industrial Units", International Journal of Scientific Research in Science and Technology (IJSRST), Online ISSN : 2395-602X, Print ISSN : 23956011, Volume 7 Issue 6, pp. 43-50, NovemberDecember 2020. Available at doi $\quad$ : https://doi.org/10.32628/IJSRST20768 Journal URL : http://ijsrst.com/IJSRST20768 